\title{
Jaydess ${ }^{\circledR}$ levonorgestrel intrauterine system
}

Louise Melvin, ${ }^{1}$ John Scott, ${ }^{2}$ Julie Craik ${ }^{2}$
${ }^{1}$ Director, Faculty of Sexual \& Reproductive Healthcare (FSRH) Clinical Effectiveness Unit, Glasgow, UK

${ }^{2}$ Researcher, FSRH Clinical Effectiveness Unit, Glasgow, UK

\section{Correspondence to} Dr Louise Melvin, FSRH Clinical Effectiveness Unit, Sandyford, 2-6 Sandyford Place, Glasgow G3 7NB, UK; louise.melvin@nhs.net

Received 20 May 2014 Accepted 20 May 2014

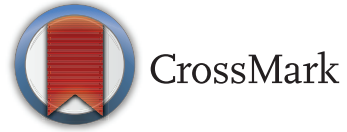

To cite: Melvin L, Scott J, Craik J. J Fam Plann Reprod Health Care 2014;40: 165-169.

\section{BACKGROUND}

Intrauterine contraception is available as either copper-containing intrauterine devices (Cu-IUDs) or a levonorgestrel intrauterine system (LNG-IUS). ${ }^{1}$ Until recently the Mirena ${ }^{\circledR}$ LNG-IUS (Bayer plc) which contains $52 \mathrm{mg}$ levonorgestrel has been the only licensed LNG-IUS available in the UK.

Jaydess ${ }^{\circledR}$ (Bayer plc) is a LNG-IUS that was launched in the UK market in April 2014. It has been designed with smaller dimensions than Mirena. As a result the LNG content and release rate are lower (Tables 1 and 2). It is known as Skyla ${ }^{\circledR}$ in the USA, where it has been licensed since 2013. ${ }^{6}$ Jaydess will not replace Mirena but is instead intended to afford women greater contraceptive choice. The differences and similarities between Jaydess and Mirena are summarised in Box 1. ${ }^{7}$

This article has been produced for the Journal of Family Planning and Reproductive Health Care by the Faculty of Sexual \& Reproductive Healthcare (FSRH) Clinical Effectiveness Unit (CEU) and is based on their recent New Product Review. $^{7}$

\section{AVAILABLE EVIDENCE}

Clinical studies have examined various strengths and sizes of LNG-IUS. The terminology in the literature is inconsistent as some studies describe the different LNG-IUS devices according to their LNG content, whereas others use the LNG release rate. For consistency the LNG content is used in this review. Here we evaluate the available evidence, highlighting the differences and potential benefits of Jaydess, which contains 13.5 mg LNG.

Data from Phase II and III studies have been reported in three publications. Gemzell-Danielsson et al. ${ }^{8}$ conducted a randomised Phase II study of Jaydess, Mirena and an intermediate-dose LNG-IUS releasing $16 \mu \mathrm{g} /$ day (LNG content $19.5 \mathrm{mg})$. Nelson et al. ${ }^{9}$ compared two doses of LNG-IUS (Jaydess and LNG-IUS $19.5 \mathrm{mg}$ ) in a randomised Phase III study. The LNG-IUS $19.5 \mathrm{mg}$ is not licensed or available commercially. A recent publication has reported pooled pharmacokinetic and pharmacodynamic analyses from the Phase II and III studies. ${ }^{10}$

Randomised studies comparing Jaydess with the etonogestrel implant $\left(\right.$ Nexplanon $\left.{ }^{\circledR}\right)$
Table 1 Product differentiation between Jaydess ${ }^{\circledR}$ and Mirena ${ }^{\circledR}$

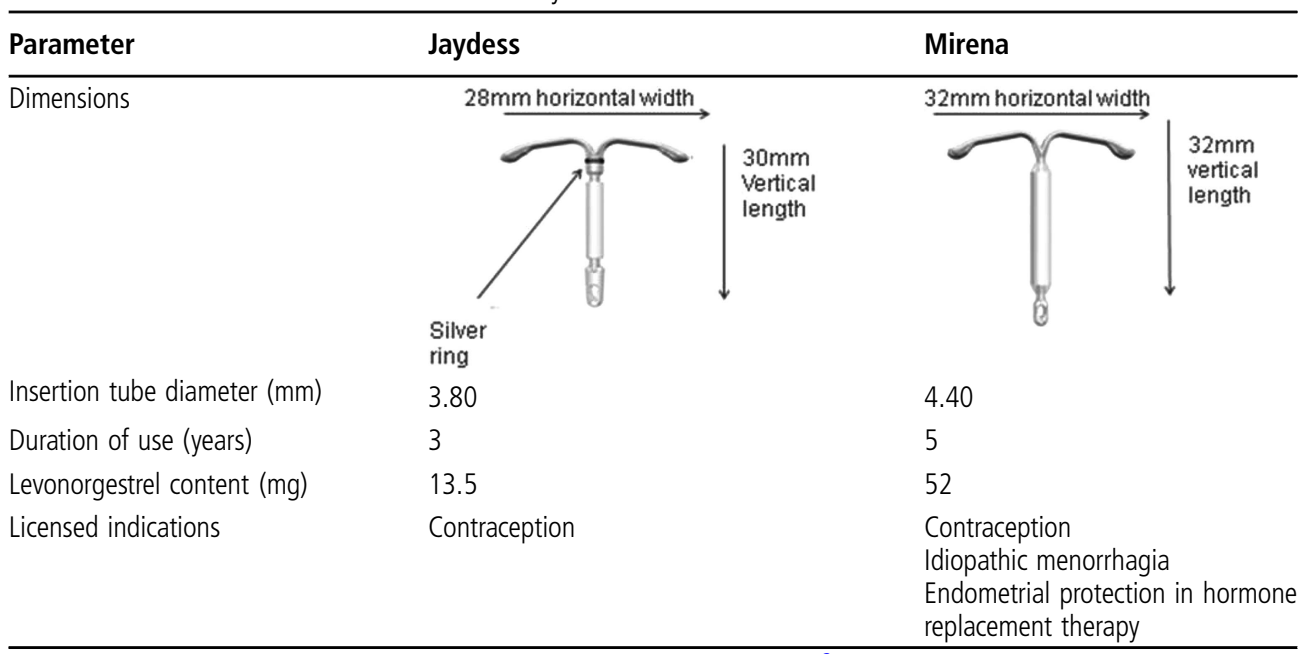

Table and images reproduced with the kind permission of Bayer Healthcare. ${ }^{2}$ 
Table 2 Levonorgestrel release rates and serum levels* associated with the Jaydess ${ }^{\circledR}$ and Miren ${ }^{\circledR}{ }^{\circledR}$ intrauterine systems

\begin{tabular}{|c|c|c|c|c|}
\hline \multirow[b]{2}{*}{ Time from insertion } & \multicolumn{2}{|c|}{$\begin{array}{l}\text { Release rate } \\
(\mu \mathrm{g} / \text { day) }\end{array}$} & \multicolumn{2}{|c|}{$\begin{array}{l}\text { Serum level } \\
(\mathrm{pg} / \mathrm{ml}) \dagger\end{array}$} \\
\hline & Jaydess $^{3}$ & Mirena $^{4}$ & Jaydess $^{3}$ & Mirena $^{5}$ \\
\hline 24 hours & 14 & 20 & - & - \\
\hline 60 days & 10 & - & - & - \\
\hline 1 year & 6 & - & 162 & 191 \\
\hline 2 years & - & - & - & 157 \\
\hline 3 years & 5 & - & 59 & 134 \\
\hline 4 years & NA & 12 & NA & - \\
\hline 5 years & NA & 10 & NA & - \\
\hline 6 years & NA & - & NA & 133 \\
\hline \multicolumn{5}{|c|}{$\begin{array}{l}\text { "The release rates and serum levels were not measured for Jaydess and } \\
\text { Mirena at the same time points and in the same way. } \\
\text { tThe contraceptive effect of the levonorgestrel intrauterine system is } \\
\text { predominantly a local effect, therefore systemic serum levels should not be } \\
\text { assumed to be an indicator of efficacy or of other local effects. } \\
\text { NA, data not available. }\end{array}$} \\
\hline
\end{tabular}

and with a combined oral contraceptive pill (Yasmin ${ }^{\circledR}$ ) have been conducted to assess user satisfaction, discontinuation rates and other parameters, but had not been published at the time of preparation of this New Product Review. The manufacturer has informed us that a study of Jaydess use by very young women (aged under 18 years) has been undertaken, but that results are not yet available.

\section{HOW EFFECTIVE IS JAYDESS?}

In the Phase II randomised controlled trial (RCT) that compared 239 women using Jaydess (LNG-IUS $13.5 \mathrm{mg}$ ) to 245 women using LNG-IUS $19.5 \mathrm{mg}$ and 254 women using Mirena (LNG-IUS $52 \mathrm{mg}$ ) the reported Pearl indices were 0.17 [95\% confidence interval (95\% CI) $0.00-0.93$ ]; 0.82 (95\% CI 0.27 $1.92)$ and 0 (95\% CI $0-0.59)$, respectively. ${ }^{8}$

The Phase III RCT including 1432 Jaydess users showed a Pearl index of 0.41 (95\% CI 0.13-0.96) at 1 year and a cumulative Pearl index after 3 years' use of 0.33 pregnancies per 100 woman-years $(95 \%$ CI $0.16-$ $0.60)$. In the 1452 women using LNG-IUS $19.5 \mathrm{mg}$ a similar Pearl index of 0.31 per 100 woman-years $(95 \%$ CI $0.15-0.57)$ was reported at 3 years. ${ }^{9}$ The KaplanMeier estimate for the cumulative failure rate of Jaydess over 3 years was $0.9 \% .^{9}$ Directly comparable figures are unavailable, but the Summary of Product Characteristics (SPC) for Mirena ${ }^{4}$ quotes a cumulative failure rate of $0.7 \%$ at 5 years, and the National Institute for Health and Care Excellence (NICE) guideline quotes a failure rate for the Mirena IUS as fewer than $1.0 \%$ at 5 years. ${ }^{11}$

In both Phase II and III studies, assessment of cervical mucus showed low Insler scores with use of all LNG-IUS doses, indicating very similar progestogenic effects on cervical mucus. ${ }^{10}$ A lower incidence of anovulation was observed in Jaydess users than in Mirena users but ovulation was observed in the majority of women in all three LNG-IUS groups. ${ }^{10}$
Box 1 Key differences and similarities between Jaydess ${ }^{\circledR}$ and Mirena ${ }^{\circledR}$ (adapted from Ref. 7 with permission)

Key differences from the Mirena LNG-IUS

- The core of the Jaydess levonorgestrel intrauterine system (LNG-IUS) contains $13.5 \mathrm{mg}$ LNG compared with $52 \mathrm{mg}$ LNG in the Mirena LNG-IUS

- Jaydess is licensed for 3 years, whereas Mirena is licensed for 5 years of contraceptive use

- Jaydess has a smaller frame and narrower inserter tube

- The release rates and serum levels of LNG are lower

- Jaydess is only licensed for contraception (see licensed indications in Table 1)

- Women using Jaydess are less likely to experience amenorrhoea

- Higher failure rates and ectopic pregnancy rates have been reported in some trials of Jaydess but numbers are currently too small to confirm a significant difference

- Jaydess carries a silver ring on its stem that distinguishes it from other intrauterine devices on ultrasound scan or X-ray

- Safety and efficacy information for Jaydess in women aged under 18 years is not yet available

- The Summary of Product Characteristics (SPC) for Jaydess states that it is not a first choice for contraception in nulliparous women as clinical experience is limited

\section{Similarities to the Mirena LNG-IUS}

- Other adverse events in clinical studies are similar to the adverse event profile of the Mirena LNG-IUS

- The technique for loading and inserting Jaydess is the same as for the current Mirena insertion device

- As with the Mirena LNG-IUS, the SPC for Jaydess advises insertion within 7 days of the onset of menstruation, or replacement at any time in the cycle

- Faculty of Sexual \& Reproductive Healthcare recommendations for Mirena ${ }^{1}$ would apply when inserting Jaydess at other times in the cycle, after abortion or childbirth, or when switching to Jaydess from other methods

\section{Benefits}

- In theory Jaydess may be easier to insert and may result in less pain at insertion than Mirena but there have been no comparisons with the currently available Mirena product

\section{HOW DO SIDE EFFECTS AND BLEEDING PATTERNS COMPARE?}

Despite lower serum levels of LNG with Jaydess, current evidence does not suggest any clinically significant advantage in terms of the side effect profile. 
The trial data ${ }^{8}$ showed a decrease in the number of bleeding or spotting days over time from insertion with all doses of LNG-IUS. There were more days with spotting only than with bleeding in all reference periods. The main difference appears to be a lower rate of amenorrhoea in Jaydess users. In the Jaydess, LNG-IUS $19.5 \mathrm{mg}$ and Mirena groups the proportion of subjects with amenorrhoea increased from 2.7\%, $6.1 \%$ and $5.9 \%$, respectively, in the second 90-day reference period (3-6 months after insertion) to $12.7 \%, 18.9 \%$ and $23.6 \%$ of subjects in the final reference period from 33 to 36 months $(p=0.12$ for Jaydess vs Mirena). While a lower amenorrhoea rate may appeal to some women, it may be perceived as a disadvantage by others.

\section{HOW SHOULD JAYDESS BE USED?}

The insertion and removal procedures for Jaydess are similar to those for Mirena. The SPC for Jaydess states that health care professionals should ensure that they are experienced in IUS insertions or that they have undergone training in the Jaydess insertion procedure. $^{3}$ The FSRH advises that health professionals offering intrauterine contraception should hold the FSRH Letter of Competence or have achieved equivalent recognised competencies.

In clinical trials there was no difference in rates of non-placement of Jaydess or Mirena. Health care professionals reported that the placement of lower-dose LNG-IUS devices was easier than placement of Mirena in both nulliparous and parous women. ${ }^{8} 9$ However, the Mirena IUS inserter used in the trials was different to the currently available Mirena product, which has a more ergonomic insertion system, the Evoinserter ${ }^{\mathrm{TM}}{ }^{12}$ The Jaydess inserter is similar in design to the Evoinserter. The Mirena insertion system used in the trials was also broader (diameter $4.75 \mathrm{~mm}$ ) than the current inserter. No studies have compared ease of insertion of the currently available Mirena product (inserter diameter $4.4 \mathrm{~mm}$ ) with insertion of Jaydess (inserter diameter $3.8 \mathrm{~mm}$ ).

\section{WHAT IS THE RISK OF ECTOPIC PREGNANCY?}

It is well known that the absolute risk of ectopic pregnancy is reduced in women using any form of contraception, but that if a pregnancy occurs during IUD use the relative risk of ectopic pregnancy is increased.

The SPC for Jaydess quotes an ectopic pregnancy rate of 0.11 per 100 woman-years, and warns that approximately half of any pregnancies that occur during Jaydess use are likely to be ectopic. ${ }^{3}$ Women who have been amenorrhoeic during IUS use may have delayed awareness of pregnancy symptoms. The SPC for Jaydess advises that women are informed of the signs, symptoms and risks of ectopic pregnancy. The possibility of pregnancy should be considered in women with symptoms such as a change in bleeding pattern or pain.
If a pregnancy is diagnosed during use of any IUD, whether copper or LNG, it is important to establish its location as early as possible. The proportion of ectopic to intrauterine pregnancies reported in IUD users may vary with the type of device and the extent to which the study population is monitored. NICE guidance states that if a woman becomes pregnant with a Mirena IUS in situ, the risk of the pregnancy being ectopic is about 1 in $20 .{ }^{11}$ However, a range of figures is reported in the literature, with one crosssectional study reporting that approximately half of the pregnancies reported in women with Mirena devices in situ were ectopic. ${ }^{13}$

Ectopic pregnancy rates in Jaydess and Mirena LNG-IUS users are in fact difficult to compare because the total number of reported pregnancies in Jaydess users has been low. There was one ectopic pregnancy out of two Jaydess failures in Phase II studies, and three ectopic pregnancies out of seven failures in Phase III studies. ${ }^{14}$ In the study that included Mirena, the ectopic pregnancy rate was nonsignificantly increased in Jaydess users compared with Mirena users; the ectopic rate was highest in women using the intermediate-dose LNG-IUS $19.5 \mathrm{mg}$. The Phase III data also showed a non-significantly higher ectopic pregnancy rate in the LNG-IUS $19.5 \mathrm{mg}$ group (0.22 per 100 woman-years) compared to the Jaydess group (0.10 per 100 woman-years). Therefore, the data do not support a dose-response effect on the ectopic pregnancy rate. Furthermore, the ectopic pregnancy rates in the Jaydess studies are expressed as woman-years, preventing direct comparison with the rates quoted in the literature for Mirena ( 1 in 1000 in 5 years ${ }^{11}$ and $0.1 \%$ per year ${ }^{4}$ ).

These limitations and the lack of a dose-response effect mean that differences in the absolute and relative risks of ectopic pregnancy between different dose LNG-IUS devices should be interpreted with caution until more pregnancy data are available.

\section{HAVE OTHER ADVERSE EVENTS HAVE BEEN REPORTED?}

In Phase III studies the cumulative risk of expulsion of Jaydess was reported as $4.56 \%$ over 3 years of use. ${ }^{9}$ Data from the Phase II study ${ }^{8}$ showed that significantly fewer ovarian cysts $>3 \mathrm{~cm}$ in diameter were observed in groups using the two lower-dose LNG-IUS than in Mirena users, with the lowest risk in Jaydess users: $22.0 \%$ risk in Mirena users; $8.6 \%$ for LNG-IUS $19.5 \mathrm{mg}$ and $5.9 \%$ in Jaydess users $(p<0.0001)$. Functional ovarian cysts are progestogenrelated and this therefore does appear to be a doseresponse effect. The Phase III trial observed no reduction from baseline in bone mineral density in either the lumbar spine or hip over 3 years in the LNG-IUS 13.5 mg group. ${ }^{9}$ 


\section{ARE THERE ANY RESTRICTIONS ON USE?}

The UK Medical Eligibility Criteria for Contraceptive Use (UKMEC) ${ }^{14}$ is an agreed set of criteria for providing contraception to men or women with a range of medical conditions. Jaydess was not available in the UK when the UKMEC were last updated. The FSRH CEU therefore recommends that the UKMEC classifications for the LNG-IUS are used for Jaydess. This means that according to FSRH guidance, use of Jaydess in women under 18 years of age should not generally be restricted (UKMEC 2 from menarche to $<20$ years: benefits generally outweigh the risks). Under UKMEC there are no restrictions on use of LNG-IUS in nulliparous women. However, the SPC for Jaydess states that it is not a first choice for contraception in nulliparous women as clinical experience is limited.

\section{ARE THERE ANY DRUG INTERACTIONS?}

Theoretically, because Jaydess and Mirena contain the same contraceptive hormone and have a similar local mechanism of action, drug interactions with Jaydess should be broadly similar to those for Mirena. The influence of drugs that induce or inhibit hepatic microsomal enzymes on the efficacy of Jaydess is not known, but this is not believed to be of significance due to its local mechanism of action.

\section{USER SATISFACTION AND PAIN}

Satisfaction rates were high and discontinuation low across all LNG-IUS groups. Neither of the clinical trials used a validated measure of pain. ${ }^{8} 9$ Subjects were asked to rate pain during placement as 'none', 'mild', 'moderate' or 'severe'. The need for cervical dilatation, local anaesthesia or pain medication was at the physician's discretion. These outcomes were recorded but it is not clear how they influenced women's perception of pain. Of the subjects in the combined Jaydess/LNG-IUS $19.5 \mathrm{mg}$ group, 350/484 $(72.3 \%)$ reported 'no pain' or 'mild pain' compared with $147 / 254(57.9 \%)$ in the Mirena group $(p<0.001){ }^{7}$ There is as yet no evidence regarding differences in pain associated with insertion of the currently available Mirena IUS and Jaydess.

\section{COST}

The unit price for Jaydess to the National Health Service is $£ 69.22$. The net price for Mirena is $£ 88.00 .^{15}$ Comparisons of the costs of contraceptive methods are difficult, both because of the numerous ancillary costs associated with their provision and because of their differing durations of use.

A study in the USA has suggested that women switching to the LNG-IUS $13.5 \mathrm{mg}$ from a shortacting method may generate cost savings, principally via a decrease in costs associated with unplanned pregnancy expenditure, and that there may also be savings in terms of contraceptive costs in the long term. ${ }^{16}$ No cost-effectiveness comparisons were identified with Mirena or the potentially cheaper 'hybrid' LNG-IUS products that are being introduced for treatment of heavy menstrual bleeding and that might ultimately be licensed for contraception. ${ }^{17}$

\section{WHAT DOES JAYDESS ADD TO THE RANGE OF CONTRACEPTIVES ALREADY AVAILABLE?}

The LNG-IUS $13.5 \mathrm{mg}$ Jaydess is a potentially useful addition to the range of long-acting reversible contraceptives (LARCs) that is currently available. Jaydess may appeal to women who prefer to have regular bleeding rather than amenorrhoea, although amenorrhoea may still occur. It may also be useful for women wishing to space their pregnancies but with reasonable expectation that they will wish to conceive within a 3 -year timeframe. The smaller dimensions of Jaydess may prove to be an advantage in terms of ease of fitting and reduced pain associated with insertion, particularly in young, nulliparous women. However, there is a lack of data on its use in young women and there have not been any direct comparisons with the Mirena product currently in use; therefore more robust data are required to confirm such advantages.

Acknowledgements The authors thank the FSRH Clinical Effectiveness Committee for their assistance with peer reviewing the CEU New Product Review ${ }^{7}$ on which this article is based.

Competing interests None.

Provenance and peer review Commissioned; internally peer reviewed.

\section{REFERENCES}

1 Faculty of Sexual \& Reproductive Healthcare Clinical Effectiveness Unit. Intrauterine Contraception. 2007. http:// www.fsrh.org/admin/uploads/CEUGuidanceIntrauterine ContraceptionNov07.pdf [accessed 30 April 2014].

2 Bayer Healthcare. Formulary template. Jaydess $13.5 \mathrm{mg}$ intrauterine delivery system (levonorgestrel). Contraception for up to 3 years. London, UK: Bayer Healthcare, 2014.

3 Bayer plc. Summary of Product Characteristics: Jaydess 13.5 mg intrauterine delivery system. 2014. http://www.medicines. org.uk/emc/medicine/28672/SPC/Jaydess $+13.5+\mathrm{mg}$ +intrauterine+delivery+system/ [accessed 30 April 2014].

4 Bayer plc. Summary of Product Characteristics: Mirena. 2008. http://www.medicines.org.uk/EMC/medicine/1829/SPC/Mirena/ [accessed 30 April 2014].

5 Seeber B, Ziehr SC, Gschlieber A, et al. Quantative levonorgestrel plasma level measurements in patients with regular and prolonged use of the levonorgestrel-releasing intrauterine system. Contraception 2012;86:345-349.

6 Bayer Healthcare. Highlights of Prescribing Information: Skyla. 2014. http:/labeling.bayerhealthcare.com/html/products/pi/ Skyla_PI.pdf [accessed 30 April 2014].

7 Faculty of Sexual \& Reproductive Healthcare Clinical Effectiveness Unit. New Product Review: Jaydess ${ }^{\circledR}$ Levonorgestrel Intrauterine System (LNG-IUS). 2014. http://www.fsrh.org/pdfs/CEUProductReviewJaydess.pdf [accessed 13 May 2014]. 
8 Gemzell-Danielsson K, Schellschmidt I, Apter D. A randomized, phase II study describing the efficacy, bleeding profile, and safety of two low-dose levonorgestrel-releasing intrauterine contraceptive systems and Mirena. Fertil Steril 2012;97:616-622.

9 Nelson A, Apter D, Hauck B, et al. Two low-dose levonorgestrel intrauterine contraceptive systems: a randomized controlled trial. Obstet Gynecol 2013;122:1205-1213.

10 Apter D, Gemzell-Danielsson K, Hauck B, et al. Pharmacokinetics of two low-dose levonorgestrel-releasing intrauterine systems and effects on ovulation rate and cervical function: pooled analyses of phase II and III studies. Fertil Steril. Epub ahead of print: 10 April 2014. doi:10.1016/j.fertnstert.2014.03.004.

11 National Institute for Health and Clinical Excellence (NICE). Long-acting Reversible Contraception: The Effective and Appropriate Use of Long-acting Reversible Contraception. 2005. http://www.nice.org.uk/pdf/CG030fullguideline.pdf [accessed 30 April 2014].

12 Faculty of Sexual \& Reproductive Healthcare Clinical Effectiveness Unit. Faculty Statement: New Inserter for
Mirena ${ }^{\circledR}$ IUS. 2012. http://www.fsrh.org/pdfs/CEUstatement NewMirenaInserter.pdf [accessed 30 April 2014].

13 Backman T, Rauramo I, Huhtala S, et al. Pregnancy during the use of levonorgestrel intrauterine system. Am J Obstet Gynecol 2004;190:50-54.

14 Faculty of Sexual \& Reproductive Healthcare. UK Medical Eligibility Criteria for Contraceptive Use (UKMEC 2009). 2009. http://www.fsrh.org/pdfs/UKMEC2009.pdf [accessed 30 April 2014].

15 Joint Formulary Committee. British National Formulary. British National Formulary (BNF 65). London, UK: British Medical Association and Royal Pharmaceutical Society, 2013.

16 Trussell J, Hassan F, Henry N, et al. Cost-effectiveness analysis of levonorgestrel-releasing intrauterine system (LNG-IUS) $13.5 \mathrm{mg}$ in contraception. Contraception 2014;89:451-459.

17 Mithra Pharmaceuticals. Summary of Product Characteristics: Tresovelle. 2014. http://www.mhra.gov.uk/home/groups/spcpil/ documents/spcpil/con1390198538525.pdf [accessed 30 April 2014].

\section{FACULTY OF SEXUAL \& REPRODUCTIVE HEALTHCARE MEMBERSHIP EXAMINATION}

The Membership Examination (MFSRH) consists of:

\section{Part 1 Single Best Answer paper (SBA)}

The London-based examination is held annually in April and October. Applications for the Friday 24 October 2014 examination must be received by 1 July 2014 and for the Friday 17 April 2015 examination by 3 January 2015. The syllabus for the Part 1 is on the Faculty website.

\section{Evidence Based Commentary (EBC)}

Candidates can view the released topic and candidate guidance notes for EBC on the Faculty website. There is an absolute deadline of 31 August 2014 to submit the EBC on this topic.

\section{口 Part 2 Examination}

Applications for the MFSRH Part 2 to be held in Liverpool in June $\mathbf{2 0 1 5}$ must be received by $\mathbf{3}$ January 2015.

Further information and the Part 2 Syllabus are on the Faculty website. The qualification is subject to re-certification every 5 years. For the current MFSRH Examination Regulations, information on all components of the MFSRH examination and application forms, please visit the Faculty of Sexual and Reproductive Healthcare website: www.fsrh.org (Examinations) or e-mail Denise Pickford: denise@fsrh.org. 